\title{
Emerging flaviviruses: the spread and resurgence of Japanese encephalitis, West Nile and dengue viruses
}

\author{
John S Mackenzie ${ }^{1}$, Duane J Gubler ${ }^{2}$ \& Lyle R Petersen ${ }^{3}$
}

\begin{abstract}
Mosquito-borne flaviviruses provide some of the most important examples of emerging and resurging diseases of global significance. Here, we describe three of them: the resurgence of dengue in tropical and subtropical areas of the world, and the spread and establishment of Japanese encephalitis and West Nile viruses in new habitats and environments. These three examples also illustrate the complexity of the various factors that contribute to their emergence, resurgence and spread. Whereas some of these factors are natural, such as bird migration, most are due to human activities, such as changes in land use, water impoundments and transportation, which result in changed epidemiological patterns. The three examples also show the ease with which mosquito-borne viruses can spread to and colonize new areas, and the need for continued international surveillance and improved public health infrastructure to meet future emerging disease threats.
\end{abstract}

Emerging diseases are defined as diseases that have newly appeared in a population or have existed previously but are rapidly increasing in incidence or geographic range ${ }^{1}$. Mosquito-borne members of the genus Flavivirus in the family Flaviviridae provide some of the most important examples of emerging diseases, as well as one of the earliest documented examples of the spread of a disease into a new geographic area: yellow fever from West Africa into the Americas in the seventeenth and eighteenth centuries, which was probably carried by vessels used in the slave trade. More recently, the enormous resurgence of dengue in the tropical and subtropical areas of the world, the emergence of West Nile in North America and the spread of Japanese encephalitis through much of Asia and into Oceania provide excellent examples of emergence that form the basis of this article.

Most members of the Flavivirus genus are arthropod-borne, or arboviruses, a term that describes their requirement for a bloodsucking arthropod to complete their life cycle. A few members of the genus, however, have no known vector. The genus contains over 70 viruses, of which approximately 40 are mosquito-borne, 16 are tickborne and 18 have no known vector ${ }^{2}$. The type species of the genus is yellow fever virus (YFV), through which the genus and family derive their name. Although all flaviviruses are serologically related, they can also be grouped serologically into distinct groups ${ }^{3,4}$, the most important of which are the dengue serological group, the Japanese encephali-

${ }^{1}$ Australian Biosecurity Cooperative Research Centre, Curtin University of Technology, Perth, Western Australia. ${ }^{2}$ Asia-Pacific Institute of Tropical Medicine and Infectious Diseases, Leahi Hospital, Honolulu, Hawaii, USA. ${ }^{3}$ Division of Vector-Borne Infectious Diseases, National Center for Infectious Diseases, Center for Disease Control and Prevention, Fort Collins, Colorado, USA. Correspondence should be addressed to J.S.M. (j.mackenzie@curtin.edu.au)

Published online 30 November 2004; doi:10.1038/nm1144 tis serological group and a less serologically cohesive YFV group. They are positive-strand RNA viruses with a genome of about 11 kilobases. The genome RNA represents the only messenger RNA in infected cells and encodes three structural proteins ( $C$, capsid protein; prM, the membrane precursor protein that is proteolytically cleaved by a cellular protease to form the $\mathrm{M}$ protein in mature virions; and $\mathrm{E}$, envelope protein) and seven nonstructural (NS) proteins (NS1, NS2a, NS2b, NS3, NS4a, NS4b and NS5) ${ }^{5,6}$. The E glycoprotein is the most immunologically important protein.

The origin, evolution and spread of flaviviruses have been investigated by extensive genomic sequence analyses and calculating base substitution rates using sequences from the NS5, NS3 or E genes, or from complete genomic sequences ${ }^{7-16}$. The results have clearly shown that the tick-borne and mosquito-borne viruses constituted two distinct, separate evolutionary lineages ${ }^{7,8}$, that most of the viruses with no known vector were also in a distinct lineage and that the three lineages had diverged early in the evolution of the Flavivirus genus ${ }^{13}$. Taking the phylogenetic data together with the biological properties of different flaviviruses, it has been hypothesized that the Flavivirus genus evolved from an ancestral virus in Africa within the past 10,000 years ${ }^{8,12,14}$. The tick-borne lineage is believed to have diverged about 3,000 years ago, followed by the mosquito-borne viruses ${ }^{7-13,16}$. The most divergent of the mosquito-borne viruses form a clade, typified by YFV. These viruses are all found in the Old World and are largely associated with Aedes mosquitoes, and some are associated with hemorrhagic disease in primates. A subsequent divergence gave rise to further clades containing viruses associated with Aedes mosquitoes, including some causing hemorrhagic disease, exemplified by members of the dengue virus serological group; and clades associated primarily with Culex mosquitoes and causing encephalitic disease, typified by members of the Japanese encephalitis virus serological 
group ${ }^{14,15}$. The phylogenetic clustering and relationships have been in general agreement with the classification of flaviviruses using standard serological schemes ${ }^{3,4}$.

Flaviviruses are zoonoses that depend on animal species other than humans for their maintenance in nature, with the notable exception of the dengue viruses. Humans are usually incidental and dead-end hosts that do not contribute to the natural transmission cycle. Dengue viruses, however, have adapted completely to humans and are maintained in large urban areas in the tropics in human-mosquito-human transmission cycles that no longer depend on animal reservoirs, although such reservoirs are still maintained in the jungles of Africa and southeast Asia in mosquito-monkey-mosquito transmission cycles ${ }^{17,18}$.

There have been few previously unrecognized flaviviruses described in recent years. More important have been the resurgence and spread of well-known flaviviruses, particularly the mosquito-borne flaviviruses. The changing epidemiology of the different viruses is complex and unique to each virus ${ }^{18}$, and many factors and properties affect their potential to spread and colonize new areas, and to cause an increased incidence of infection. These factors are complex and not fully understood, but they are closely associated with demographic and societal changes that have occurred over the past half-century-that is, they are due in large part to human activities ${ }^{18-20}$. So, urbanization, transportation and changes in land use have been particularly conducive to emergence and resurgence of mosquito-borne diseases. In addition, other natural factors may also contribute to disease activity and virus spread, such as genetic change in the virus, host-vector relationships, bird migration and movement, climate and wind patterns. These factors provide a common thread to the following discussion.

\section{Japanese encephalitis virus}

Etiology. The Japanese encephalitis serological group of flaviviruses comprises eight virus species and two subtype viruses with a geographic range encompassing all continents except Antarctica ${ }^{21}$. The major virus species and their geographic range are as follows: the Japanese encephalitis virus (JEV) in eastern, southern and southeastern Asia, Papua New Guinea and the Torres Strait of northern Australia; the West Nile virus (WNV) in Africa, southern and central Europe, India, the Middle East and North America, and, as Kunjin virus (a subtype of WNV), in Australia and Papua New Guinea; the Murray Valley encephalitis virus (MVEV) in Australia, Papua New Guinea and the western Indonesian archipelago; and the St. Louis encephalitis virus (SLEV) in North and South America (Fig. 1). The other minor members of the group are Usutu (USUV), Koutango and Yaounde viruses in Africa; Cacipacore virus in South America; and Alfuy, a subtype of MVEV, in Australia. Most members have avian vertebrate hosts and are vectored primarily by Culex spp. mosquitoes.

JEV is the most important cause of viral encephalitis in eastern and southern Asia, with 30,000-50,000 cases reported annually ${ }^{22}$, although this may be a considerable underestimate because of inadequate surveillance and reporting. Of these cases, about $25-30 \%$ are fatal and $50 \%$ result in permanent neuropsychiatric sequelae ${ }^{23}$. Most infections are asymptomatic, with estimates ${ }^{24}$ of the ratio of symptomatic to asymptomatic infection ranging from 1 in 25 to 1 in 1,000, the variation depending on many factors ${ }^{22}$, including endemicity, exposure to mosquitoes, pre-existing antibodies to flaviviruses and virus strain differences.

Pathogenesis. The incubation period of JEV is 5-15 days. Clinical disease varies from a nonspecific febrile illness to a severe disease in which patients present with meningoencephalitis, aseptic meningitis or a polio-like acute flaccid paralysis ${ }^{22,25}$. Most clinical cases occur in infants and children, although in areas where JEV occurs for the first time or only at rare intervals, clinical disease may be found in all age groups. Patients typically present after a few days of nonspecific febrile illness, which may include cough, nausea, vomiting, diarrhea and photophobia, followed by a reduced level of consciousness. Convulsions occur frequently in children and less commonly in adults. A proportion of patients make a rapid spontaneous recovery. The classical description of Japanese encephalitis includes a Parkinsonian syndrome of dull, flat, mask-like facies with wide, unblinking eyes, tremor, generalized hypertonia, cogwheel rigidity and other abnormalities of movement ${ }^{22}$. There may also be upper motor neuron signs, cerebellar signs and cranial nerve palsies. Paralysis of the upper extremities is more common than that of the legs. About $30 \%$ of survivors have frank persistent motor deficits and about $20 \%$ have severe cognitive and language impairment.

Transmission. Much of our knowledge of the ecology of JEV has come from studies carried out in Japan by Scherer, Buescher and colleagues $^{26,27}$, and JEV ecology has been the subject of several reviews ${ }^{23,28,29,30}$. It is now well established that the virus exists in a zoonotic transmission cycle between mosquitoes and pigs and/or water birds; humans become infected only coincidentally when bitten by an infected mosquito and are a dead-end host. JEV has been isolated from many mosquito species in field studies, and although the major mosquito vectors vary in different geographic regions, the most important is Culex tritaeniorhynchus. Pigs are the main component in the transmission cycle with respect to human infection, whereas herons, egrets and other ardeid birds are important maintenance hosts. Of other vertebrate species, horses can develop central nervous system (CNS) infections but are a dead-end host; other domestic animals become infected, but show no evidence of viremia; rodents are refractory to infection; and amphibians, reptiles and bats can become infected experimentally and virus can persist, but the role of these species in overwintering and maintenance of the virus in the environment is not known.

There are two epidemiological patterns of transmission: an endemic pattern in tropical areas with virus circulation in most months of the year, but with a broad seasonal peak probably resulting from irrigation practices; and an epidemic pattern in more temperate areas with clear summer seasonality ${ }^{30}$. So, Japanese encephalitis is largely a rural disease, with $C x$. tritaeniorhynchus mosquitoes breeding in rice paddies and pigs providing the main source of blood meals, with the consequence of transmission cycles in close proximity to human habitation. Changing epidemiological patterns may be occurring in some areas, however, where pig husbandry has improved through collective pigsties and urban mosquito species, such as CX. quinquefasciatus, have replaced paddy field breeding species (J.P. Gonzalez, unpublished data).

Epidemiology and phylogenetic variation. Historically, epidemics of encephalitis have been recognized in Japan since the 1870s. JEV was first isolated from the brain of a fatal human case in 1935. It has subsequently been found throughout most of eastern and southern Asia $^{23,30,31}$. The apparent temporal spread of JEV in Asia over the past five decades can be traced by the approximate date of the first report of epidemic activity $23,29,30,31$. In the 1990s, JEV spread westward into southern Pakistan for the first time ${ }^{32}$, although its establishment there has never been confirmed, into the Haryana ${ }^{33}$ and Kerala ${ }^{34}$ states in northwestern and southwestern India, respectively, and eastwards into the western Indonesian archipelago, New Guinea and northern Australia ${ }^{35-38}$. The latter spread was unexpected, as it had long been held that JEV was restricted to the Oriental zoogeographic region, as 


\section{REVIEW}

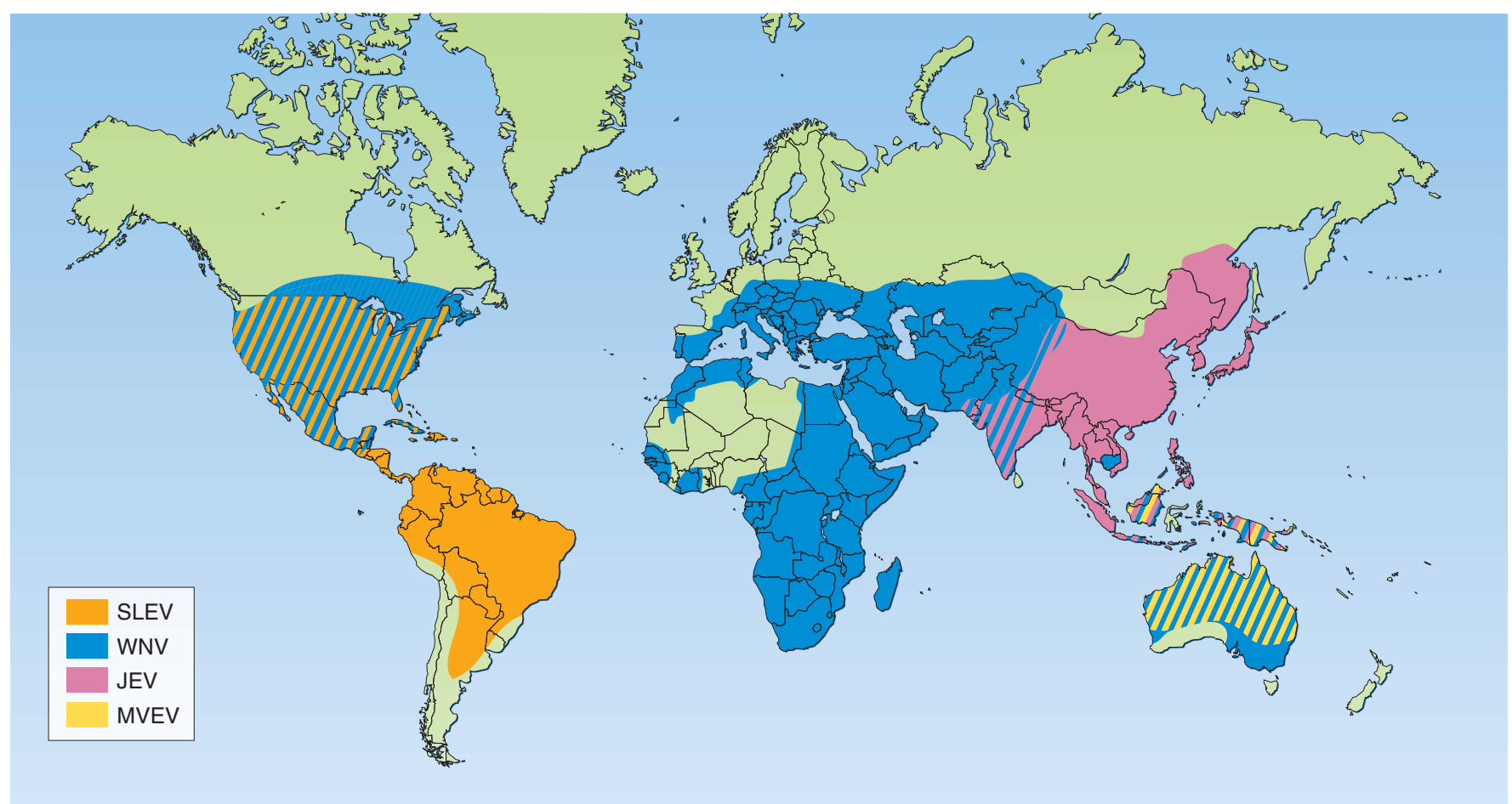

Figure 1 The global distribution and spread of the major Japanese encephalitis serological group members. This map was based on a map of the distribution of Japanese encephalitis serological group viruses prepared by United States Centers for Disease Control and Prevention Division of Vector-Borne Infectious Diseases, but altered to reflect the spread of West Nile virus in North and Central America.

defined by the hypothetical Wallace Line, and that its close relative, MVEV, was the encephalitic flavivirus in the Australasian zoogeographic region $37,39,40$. Burke and Leake ${ }^{23}$ and Endy and Nisalak ${ }^{29}$ have described the current geographic range of JEV.

Phylogenetic studies of a number of JEV isolates from different geographic areas using limited nucleotide sequencing in the highly variable prM gene suggested that there are at least four JEV genotypes ${ }^{41,42}$. These findings were confirmed using sequences from the E gene $e^{43-45}$, and the number of genotypes extended to a possible fifth genotype ${ }^{46}$. Most virus strains of genotype I were isolated from northern Thailand, Cambodia and Korea; those from genotype II were isolated from southern Thailand, Malaysia, Indonesia and Australia; those from genotype III were isolated from areas of Asia that are largely temperate, such as Japan, Korea, China, Taiwan, Philippines, India and Sri Lanka; and those from genotype IV have only been isolated from Indonesia ${ }^{41,42,45}$. A strain isolated in 1952 from Malaysia, Muar strain, may represent the only known example of a fifth genotype ${ }^{46}$. Most isolates, including the prototype Nakayama strain, belong to genotype III, the most widely distributed genotype and the only genotype found in the Indian subcontinent. So, genotypes I and III occurred principally in temperate, epidemic areas, and genotypes II and IV occurred principally in tropical, endemic regions.

This observation led to the hypothesis that genetic differences might correlate with epidemic potential ${ }^{41,42,45}$, but further analysis of isolates from different geographic areas found several anomalies, especially with respect to movement from epidemic to endemic areas. So, isolates of epidemic genotype III were found in various endemic areas, such as Indonesia, southern Vietnam ${ }^{45}$ and Malaysia ${ }^{47}$. Epidemic genotype I isolates were found in Malaysia ${ }^{47}$, and the same genotype has also recently become established in the Torres Strait of northern Australia ${ }^{48}$. In addition to these anomalies, there has been a shift in the predominant genotype in some epidemic areas, with genotype III viruses being supplanted by genotype I viruses. This has been observed in Japan ${ }^{49,50}$, Korea ${ }^{51}$ and northern Vietnam ${ }^{50}$ during the early to mid-1990s.

Some caution had rightly been expressed about phylogenetic analyses using limited nucleotide sequences ${ }^{6}$, especially with the recent evidence indicating the occurrence of homologous recombination with $\mathrm{JEV}^{52}$; however, further studies of JEV phylogeny with full-length genomic sequences have supported the findings from the limited sequence data ${ }^{45,53}$, particularly sequences from the E gene. Nevertheless, although there are 30 full-length genomic sequences, there is an imbalance in their selection, with most belonging to genotype III.

Virus evolution and spread. The mechanisms by which JEV emerges and establishes in new areas are not well understood. It had long been thought that a major factor was changing land usage and agricultural practices whereby deforestation or agricultural changes led to increased paddy field development for rice growing ${ }^{54}$. Although this undoubtedly has a role in establishing endemic foci, it does not in itself reflect how the virus arrives in the new area. The three mechanisms most likely to assist in spread are wind-blown mosquitoes, bird migration and the movement or transportation of infected people. In the 1995 outbreak in the Torres Strait, it was hypothesized that JEV moved eastward from endemic foci in eastern Indonesia to New Guinea and the Torres Strait by a process of vagrant birds moving from island to island, and setting up a series of mosquito-pig and mosquito-bird transmission cycles ${ }^{55}$. It was suggested that subsequent movement across the Torres Strait into northern mainland Australia was through the movement of infected mosquitoes blown by cyclonic winds ${ }^{56}$. Indeed, there is a substantial literature on the role of wind in the genesis of epidemic activity of arboviruses through the movement of infected arthropods, including mosquitoes ${ }^{57}$, and wind is also used by $C x$. tritaeniorhynchus mosquitoes as a means of migration each year in China ${ }^{58,59}$ and for dispersion in $\operatorname{Japan}^{60}$. The mechanism by which the genotype I virus 
reached the Torres Strait in 2000 is not known, and it has been hypothesized that this new genotype might have been introduced through a migratory bird. The role of bird migration in JEV dispersal is not well understood, and many of the species implicated in JEV transmission cycles move shorter distances as vagrants. Nevertheless, there is anecdotal evidence that it may be an important mechanism for virus movement $50,61,62$.

The origin and evolution of JEV have been the subject of considerable speculation and discussion. The lineage leading to the Japanese encephalitis serological group may have diverged in Africa within the millenium ${ }^{8,11-15}$. As the closest relatives to JEV are MVEV and Alfuy virus in Australia ${ }^{21,55}$ and USUV in Africa ${ }^{21}$, an early virus in the JEV lineage might have arisen from northern Africa or western Asia, and radiated eastward to evolve JEV, MVEV and Alfuy virus, and westward to give rise to USUV ${ }^{9}$. The ancestor of JEV, however, was probably an Asian virus and may have evolved within the past 300 years ${ }^{37}$. Recent phylogenetic results suggest that JEV subsequently evolved in southeastern Asia and then dispersed to northern and eastern areas ${ }^{62}$. In support of this, it was pointed out that genotypes IV and V are the most divergent genotypes and may represent the oldest lineages, and that they and the other three lineages are all found in the Indo-Malayasian region, whereas genotypes I, II and III have dispersed elsewhere. The hypothesis raises many questions, not least of which are those related to the lack of apparent dispersal of the older genotypes, the spread of a single genotype (genotype III) to India, the possible spread or replacement of genotypes in other parts of the geographic range of JEV, and the relationship of JEV with the African virus USUV, its closest sibling. Nevertheless, it seems that the relatively recent evolution of JEV may provide the opportunity to better understand how the flaviviruses are successfully expanding and emerging into a new global habitat.

Prevention and control. The control of Japanese encephalitis is based largely on three interventions: mosquito control, avoiding human exposure and immunization. Mosquito control has been less than effective and suffers from the lack of research into new pesticides. Eliminating human exposure to infected mosquitoes, when it is feasible, is only a short-term solution. So, immunization is the only effective method for long-term protection. The currently available vaccine for use in most countries is an inactivated vaccine derived from mouse brain, which is manufactured in several regional countries ${ }^{63,64}$, but it is expensive, comprises three doses, requires boosting at relatively frequent intervals, may be less effective due to antigenic variation and gives rise to a number of vaccine-related adverse reactions.

To circumvent some of the adverse reactions, Vero cell-grown inactivated vaccines are being investigated, and some of them are currently in clinical trials. Live, attenuated vaccines seem to offer the best promise; not only do they provide long-lasting immunity, but the amount of virus needed to induce an immune response is much less, with important manufacturing advantages. The only potential vaccine, the Chinese SA14-14-2 strain, cannot be used outside China at this time, as it does not conform to the international safety requirements with respect to the cell substrate (primary hamster kidney cells), and it is also possible that the original seed virus may not have complied with good manufacturing practice. Nevertheless, it has been extensively used in China with good seroconversion (99-100\%) and efficacy (over 98\%) after two doses ${ }^{63}$. In a case-control study carried out in Nepal, an efficacy of $99.3 \%$ was reported after a single dose of the SA14-14-2 vaccine ${ }^{65}$. Two approaches are being pursued to make the vaccine more acceptable for international use: the use of a pathogen-free hamster colony for the preparation of the cell substrate and extensive testing for adventitious agents, and passage of the vaccine in Vero cells and retested in human clinical trials. The most interesting and potentially useful approach for a future Japanese encephalitis vaccine is the use of a chimeric recombinant, attenuated virus vaccine candidate based on the YFV 17D vaccine genome, in which the YFV prM and E genes are replaced by the corresponding genes from JEV strain SA-14-14-2 $2^{63,64}$. This approach has shown the chimeric vaccine to elicit a short lowlevel viremia in almost all vaccines, to be well tolerated and to induce neutralizing antibodies in all recipients ${ }^{66}$. The vaccine also protects nonhuman primates and mice against challenge with homologous and heterologous JEV genotypes ${ }^{63}$, although the mouse results using passive protection suggested that the level of protection was greater for genotypes II and III (homologous genotype) than for genotypes I or IV (ref. 67). The chimeric Japanese encephalitis vaccine (ChimeraVaxJE) is under phase 2 clinical trials with promising early results. Several other molecular approaches are under investigation, but all are still in the development phase ${ }^{64}$.

The use of inactivated Japanese encephalitis vaccine is widespread in several Asian countries with routine immunization of school-age children in Japan, Korea, China (inactivated and live attenuated vaccines), Thailand and Taiwan ${ }^{63}$. It has been suggested that Japanese encephalitis vaccine should be introduced into the Expanded Program of Immunization in countries where the burden of disease is believed to be high, but accurate information on the disease burden is lacking for most of the relevant countries. Studies are underway through the World Health Organization and the International Vaccine Institute to address this issue. The Gates Foundation has recently provided a generous donation of \$27 million to help introduce Japanese encephalitis vaccine into the Expanded Program of Immunization of countries with a substantial burden of disease.

\section{West Nile virus}

Etiology. WNV was first isolated in 1937 from the blood of a febrile woman in the West Nile district of Uganda ${ }^{68}$. The virus is now known to have an extensive distribution throughout Africa, the Middle East, parts of Europe and the former Soviet Union, south and central Asia and Australia, where it is known as Kunjin virus ${ }^{69-71}$. The virus had not been detected in North America before a 1999 New York City outbreak and its genetic similarity to strains previously identified in Israel suggested Middle Eastern importation ${ }^{72,73,74}$. Subsequently, the virus has spread rapidly throughout North America, the Caribbean and Mexico (Fig. 2). Substantial virological data have documented the spread of WNV in North America, but the data from Latin America and the Caribbean have been largely based on serological data from samples of healthy horses and birds. Curiously, reports of human or equine illness have been sparse from these regions.

Unlike other members of the Japanese encephalitis serological group, WNV can be divided genetically into two lineages ${ }^{75,76}$ : lineage 1 WNV has been most commonly associated with human disease, whereas lineage $2 \mathrm{WNV}$ strains are maintained in enzootic foci in Africa and cause occasional mild human disease $\mathrm{e}^{74,77}$. Infrequent human outbreaks caused by lineage 1 viruses were usually associated with only minor illness and were most often reported in Israel and Africa ${ }^{69,70}$, but recent outbreaks in Romania (1996), Tunisia (1997), Russia (1999), Israel (2000), and the United States and Canada (2002-2004) have each involved large numbers of patients with neuroinvasive disease. Whole and partial genome sequencing indicates that lineage 1 viruses have at least three geographically distinct clades: clade la viruses are found in Africa and have caused the recent outbreaks mentioned above; viruses in $1 \mathrm{~b}$ have been found in Australia (Kunjin); and viruses in clade $1 \mathrm{c}$ have been found in India. It is thought that the clade 1a viruses circulate between Europe and the Middle East with Africa 


\section{REVIEW}

through migratory birds. The lack of migratory pathways between other regions of the world may explain the apparent geographic segregation of clade $1 \mathrm{a}, 1 \mathrm{~b}$ and $1 \mathrm{c}$ viruses. It is possible that occasional anomalies may occur in this geographic separation, and indeed a clade $1 \mathrm{c}$ virus and a South African-like lineage 2 virus have been reported from the Volga delta in Russia ${ }^{78}$. The newly emergent clade la viruses fall into two closely related lineages: one lineage caused the recent outbreaks in Israel and the Americas and was associated with avian mortality; and the other caused the recent Romanian, Russian and Israeli (viruses of both lineages were simultaneously circulating) outbreaks, was associated with a recent equine epizootic in Italy in 1998 and was not associated with considerable avian mortality ${ }^{74,79}$. These newly emergent clade la viruses have apparent increased virulence ${ }^{80}$.

Transmission. Birds are the primary amplifying hosts, and the virus is maintained and spread in a bird-mosquito-bird cycle ${ }^{81,82}$. Humans and other vertebrates, such as horses, are incidental hosts and are thought to have a minor role in the transmission cycle, although serological data show that many species can become infected ${ }^{83}$. Wild birds develop prolonged high levels of viremia but generally remain asymptomatic; however, substantial avian mortality has occurred in Israel and the United States where similar virus strains have circulated. High mortality has been noted among American crows and other North American corvids ${ }^{81}$. It was thought that the virus would spread in the Americas by means of bird migration pathways. Spread of the virus to Caribbean islands almost certainly occurred through that route; however, the evidence in North America does not clearly indicate whether bird migration, random bird dispersal movements or both were responsible for the marked westward spread of the virus ${ }^{84}$.

The virus is transmitted by mosquitoes usually of the Culex spp. The major mosquito vector in Africa and the Middle East is $C x$. univittatus, with Cx. poicilipes, Cx. neavei, Cx. decens, Aedes albocephalus or Mimomyia spp. important in some areas ${ }^{85,86}$. In Europe, $C x$. pipiens, Cx. modestus and Coquillettidia richiardii are important. In Asia, Cx. tritaeniorhynchus, $C x$. vishnui and $C x$. quinquefasciatus predominate ${ }^{86}$. In North America, WNV has been identified in 50 mosquito species, but $C x$. pipiens, $C x$. restuans, $C x$. quinquefasciatus and $C x$.

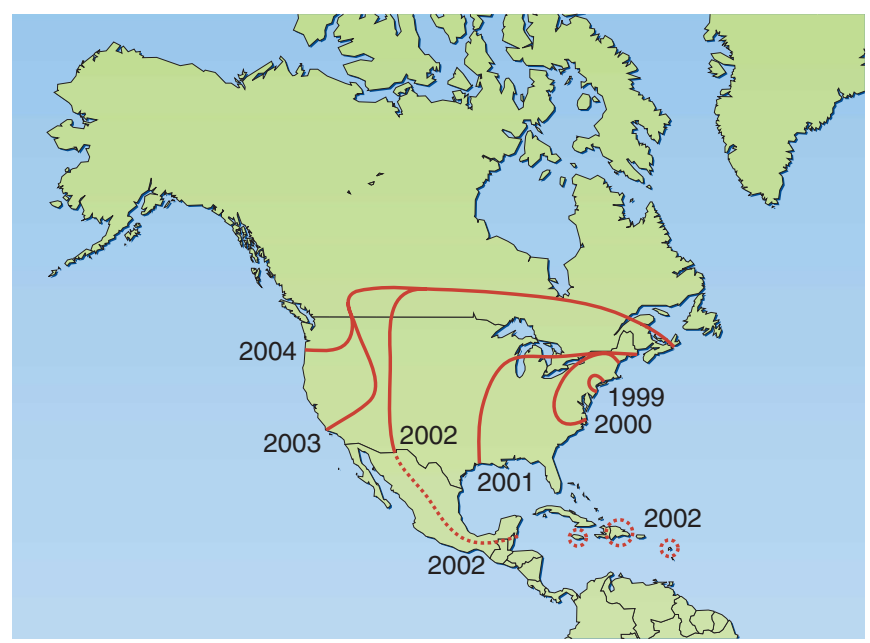

Figure 2 Approximate geographic distribution of WNV in the Americas, from 1999 to September 2004. The dark solid lines are the estimated range limits as determined by virologic surveillance of dead birds reported to the United States Centers for Disease Control and Prevention and Health Canada. The dashed lines indicate the estimated range limits as determined through published reports of serological studies of birds and horses, with the year of collection indicated. tarsalis are the main maintenance vectors ${ }^{85}$. It remains unknown which mosquito species primarily transmit WNV to humans. WNV has been recovered from ticks in Russia, but ticks have an unclear role in maintaining or disseminating the virus.

The many mosquito vectors and avian species documented with WNV in North America and its rapid geographic dispersal so far indicate that WNV eventually will be distributed throughout the Americas. This would be consistent with the distribution of SLEV, a related Japanese encephalitis serogroup virus. The low prevalence of SLEV antibodies in birds along with documented circulation of both viruses in highly endemic areas for SLEV suggests that it will not have an impact on the spread of $\mathrm{WNV}^{87}$.

Nearly all human infections result from mosquito bites, but transmission through transplanted organs and transfused blood ${ }^{88,89}$, transplacental transmission ${ }^{90}$ and occupational transmission through percutaneous exposure have occurred. Transmission through breast milk is also likely ${ }^{91}$. An outbreak among turkey-farm workers ${ }^{92}$ and possible transmission among hemodialysis patients have been reported ${ }^{93}$, although the means of viral transmission in these settings was unclear.

Pathogenesis. The pathogenesis of severe infection with WNV is not well understood. During feeding, the mosquito injects virus-laden saliva into the host. Virus may infect fibroblasts, vascular endothelial cells or cells of the reticuloendothelial system. Viremia develops, which may lead to CNS infection.

Most persons infected with WNV are asymptomatic. Illness not associated with invasive neurological disease, known as West Nile fever, is a self-limited febrile illness, occurring in about $20-30 \%$ of persons infected with $\mathrm{WNV}^{94}$. The typical incubation period ranges from 2 to 14 days, although immunosuppression may result in longer incubation periods ${ }^{88}$. West Nile fever is usually characterized by fever, headache, back pain, myalgias and anorexia persisting for 3 days to several weeks. Eye pain, pharyngitis, nausea, vomiting, diarrhea and abdominal pain can also occur. Fatigue may be prolonged ${ }^{94}$. A maculopapular rash occurs in about half the persons with West Nile fever, but is less commonly reported in persons with neuroinvasive disease $^{94,95}$. Generalized lymphadenopathy, although commonly reported in previous outbreaks, is rare in contemporary outbreaks. Myocarditis, pancreatitis and hepatitis have been described in severe infections ${ }^{22}$.

About 1 in 150 infections result in meningitis or encephalitis ${ }^{69,94}$. Movement disorders such as tremor, myoclonus and parkinsonian features including rigidity, postural instability and bradykinesia are common $^{96}$. Advanced age is the most important predictor of death 22,94 . Severe muscle weakness and a change in the level of consciousness are also risk factors for death among encephalitis patients. Among survivors, long-term cognitive and neurologic impairment may occur. Mortality among patients with neuroinvasive disease is about $10 \%{ }^{94,97}$.

WNV infection may cause an acute flaccid paralysis syndrome ${ }^{22,98}$. Although Guillain-Barré syndrome may occur, most paralysis results from an anterior horn cell process suggestive of poliomyelitis. Paralysis from WNV poliomyelitis is asymmetric and can occur without overt meningitis or encephalitis. Long-term improvement is variable, but complete recovery is uncommon. Cranial nerve abnormalities may occur. Other neurologic complications with WNV include seizures, cerebellar ataxia, brachial plexopathy and optic neuritis ${ }^{22,94}$.

Pathologic observations of fatal encephalitis showed scattered microglial nodules, mononuclear perivascular inflammatory infiltrates, and loss of neurons most predominant in the gray matter of the pons, medulla and midbrain as well as anterior horn cells of the 
spinal cord ${ }^{99}$. Viral antigens were most commonly observed inside neurons and neuronal processes in these regions, with increased at one time as an experimental treatment for cancer; the virus was isolated in spleen, lymph nodes, liver and lungs in patients who died within approximately 4 weeks after such treatment ${ }^{100}$. Persistent neurological infection has been shown in experimentally infected monkeys.

Host factors. Age is the most important host risk factor for development of neuroinvasive disease after infection ${ }^{22,69,94}$. Surveillance data from the United States indicate that risk increases about 1.5-fold for 80-90 years old compared with a child younger than 10 years ${ }^{97}$. Transplant recipients and other patients with immunosuppressive conditions seem to be at very high risk for neuroinvasive disease ${ }^{88,89,101}$. Immunosuppressed patients may have an increased propensity to develop WNV poliomyelitis and also have worse prognosis ${ }^{101}$. Notably, there are few reports of neuroinvasive disease in patients with acquired immunodeficiency syndrome. Diabetes, hypertension and cerebrovascular disease have been postulated to increase the probability of neuroinvasive disease, but these have been inconsistently identified as risk factors during outbreaks ${ }^{94}$.

Host genetics may prove important for development of neuroinvasive disease. Flavivirus resistance in some strains of laboratory inbred mice have been mapped to the interferon-inducible $2^{\prime}, 5^{\prime}$-oligoadenylate synthetase gene family ${ }^{102} \cdot 2^{\prime}, 5^{\prime}$-Oligoadenylate synthetases bind and activate a latent endoribonuclease, as well as being involved in other cellular processes such as apoptosis.

Immune responses. Humoral immunity is an essential component of the immune response to $\mathrm{WNV}$, particularly terminating viremia ${ }^{103}$. Passive transfer of immunoglobulin $G$ protects mice if administered before or shortly after lethal challenge. Furthermore, mice genetically deficient in B cells had increased WNV viral loads in the CNS, and the infection was lethal at lower doses of virus than in littermate controls. $\mathrm{T}$ lymphocytes are thought to contribute to eradicating WNV from infected cells. Mice deficient in $\gamma$-interferon-producing $\gamma \delta \mathrm{T}$ cells had greater viral loads and WNV dissemination to the $\mathrm{CNS}^{104}$. Mice deficient in $\mathrm{CD}^{+} \mathrm{T}$ cells had sustained viremia, higher $\mathrm{CNS}$ viral burdens amounts in severely immunocompromised patients. WNV was used each decade of life, resulting in a risk 30 times greater for a person

and increased mortality rates after WNV challenge; among survivors, virus was isolated from the CNS for several weeks ${ }^{105}$. Macrophage depletion was also found to influence virulence for the CNS in a mouse model.

In humans with neuroinvasive disease, IgM antibody is detectable in cerebrospinal fluid and serum in most persons within 5 days of symptom onset. At clinical presentation, nucleic acid amplification tests of cerebrospinal fluid are positive in about half the persons with neuroinvasive disease, but serum samples rarely test positive ${ }^{94}$. Immunocompromised patients may have delayed development of IgM antibodies and prolonged viremias ${ }^{89}$. The timing of the IgM antibody response in patients with WNV fever is poorly described, but serum samples obtained during clinical illness often test negative.

Progress in developing vaccines and treatment. Controlled studies to evaluate specific therapies for WNV infection have not been completed. A phase 1-2 randomized, placebo-controlled trial to assess the safety and efficacy of intravenous immune globulin containing high titers of antibody to WNV in patients with or at high risk for progression to encephalitis and/or myelitis is in progress ${ }^{106}$. A doubleblinded, placebo-controlled trial of interferon- $\alpha-n 3$ is also in progress. A trial of interferon- $\alpha$ - 2 a did not show benefit in patients with Japanese encephalitis ${ }^{107}$. The variable outcome of WNV infection warrants that uncontrolled trials or case reports should be cautiously interpreted ${ }^{96}$. Israeli patients treated with ribavirin had higher mortality than those not treated, although this difference may have resulted from patient selection.

A formalin-inactivated veterinary vaccine has been successfully used in horses, but its efficacy in avian species has not been encouraging $^{64}$. Chimeric virus vaccines containing the prM and $\mathrm{E}$ genes of WNV and the nonstructural genes of the 17D YFV vaccine strain or an attenuated dengue- 4 virus have been constructed ${ }^{64,108}$. Phase 1 clinical trials were conducted using the $17 \mathrm{D}$ YFV-WNV chimera ${ }^{64}$. A DNA vaccine has been shown to have protective efficacy in horses, mice, fish and birds and is under review for licensure as an equine vaccine ${ }^{64}$.

\section{Dengue viruses}

Etiology. The dengue virus (DENV; Fig. 3) serological group of the family Flaviviridae, genus Flavivirus, consists of four antigenically closely related virus serotypes called DEN-1, DEN-2, DEN-3 and DEN $-4^{6}$. Although there is extensive crossre-

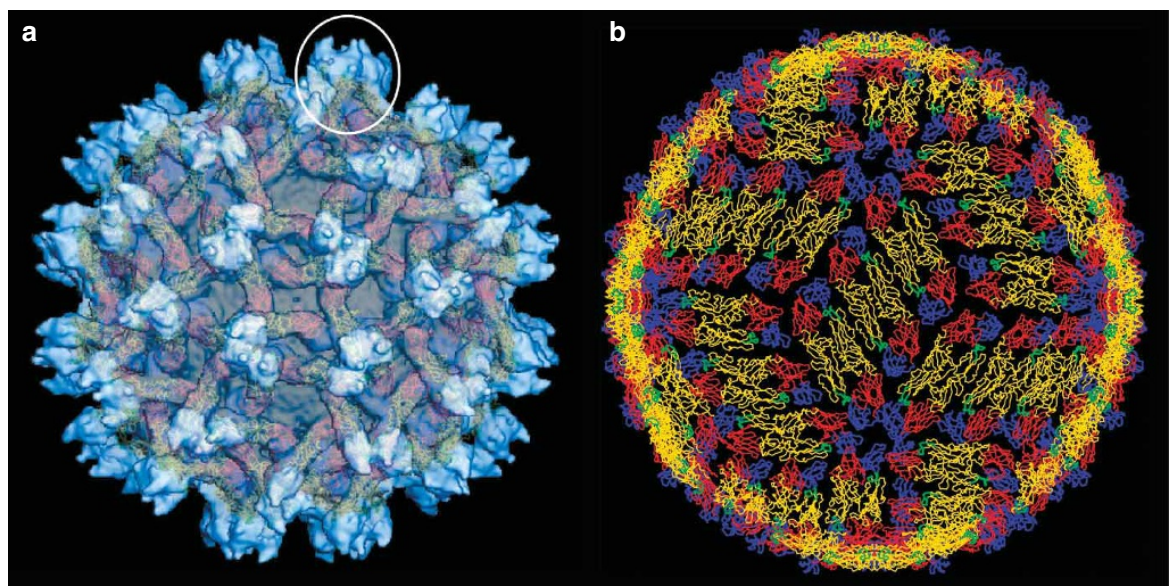

Figure 3 Dengue virus. (a) The immature dengue particle. It has 60 protein 'spikes' (circle) that jut from its surface, making it less smooth than the mature form. (b) The structure of the mature dengue virus. The virus surface is unusually smooth and its membrane is completely enclosed by a protein shell. The different domains of the protein are represented by different colors. Courtesy of R. Kuhn (Purdue University) activity among these viruses in serological tests, there is no crossprotective immunity in humans; a person living in an endemic area can have as many as four infections, one with each serotype, during their life.

DEN-1 was first isolated independently during World War II in the Pacific by Japanese and American investigators ${ }^{109,110}$, and DEN2 was isolated by the latter as well ${ }^{110}$. DEN-3 and DEN-4 were subsequently isolated in the 1950s during epidemics in the Philippines and Thailand ${ }^{111}$. Since then, thousands of viruses have been isolated from the tropics, but no new DEN serotypes have been documented ${ }^{17}$. Although it is not known where and how these viruses evolved, the evidence suggests that they were derived from a primiAfrica. The ancestor DENV is believed to have originated about 1,000 years ago, and it has tive progenitor introduced to Asia from 


\section{REVIEW}

been suggested that the zoonotic transfer of DENV from sylvatic (monkey) to sustained human transmission occurred between 125 and 320 years ago ${ }^{112}$. It is further hypothesized that the four serotypes evolved in the rainforests of southeast Asia ${ }^{17,113}$.

Each DENV serotype has been classified into genotypes on the basis of sequence data from the $\mathrm{E}$ gene or from the junction of the $\mathrm{E}$ and $\mathrm{NI}$ genes $^{114,115}$. Depending on the region sequenced, the number of genotypes within a serotype ranges from three (DEN-4) to five (DEN-1 and DEN-2). The number of genotypes probably reflects the amount of evolutionary change, which in turn reflects the amount of transmission of each serotype. Data on DEN-2 and DEN-3, in particular, suggest that selected genotypes, as well as selected strains of virus within a serotype, have greater epidemic potential and virulence ${ }^{116-121}$. The first evidence in support of this came with the introduction of DEN-2 into the Pacific and major epidemics of DEN-3 in Indonesia in the 1970s ${ }^{116,117,122}$. Also, all DEN-2 epidemics of dengue hemorrhagic fever (DHF) in the American region have been associated with a southeast Asian genotype most likely introduced to Cuba from Vietnam in 1981(refs. 17,114), and American DHF epidemics caused by DEN-3 have all been associated with a virus introduced from India, Sri Lanka or Africa ${ }^{17,118,121}$. Although not fully understood, it is clear that increased movement of viruses among countries and the resulting increased transmission have increased the rate of evolution of these viruses, which in turn has given rise to subtypes of viruses with greater epidemic potential ${ }^{123}$. Indeed, the increasing diversity of DENV, the observation of homologous recombination ${ }^{52,124-126}$ and evidence that there may be naturally occurring differences in virulence between DENV strains might suggest that we could be exposed to viruses with an expanded range of pathogenic properties in the future ${ }^{127}$.

Transmission. The DEN viruses originated and are maintained in a primitive forest transmission cycle involving canopy-dwelling Aedes spp. mosquitoes and lower primates in Asia and Africa ${ }^{128}$. In the past three centuries, the viruses became established in the urban centers of the tropics in a human-Aedes aegypti mosquito-human cycle; this transmission cycle became a major public health problem and resulted in the re-emergence of epidemic dengue fever/DHF in the twentieth century. The dengue viruses are the only known arboviruses that have fully adapted to humans, having lost the need for an enzootic cycle for maintenance $^{129}$. The principal urban vector, Ae. aegypti, is a highly domesticated mosquito that has adapted to humans, preferring to feed on them and lay their eggs in artificial containers in and around houses. Ae. aegypti is an efficient epidemic vector of DENV because of its feeding behavior, often feeding on, and thus transmitting virus to, more than one individual in a single gonotrophic cycle. Secondary vectors of DENV include Ae. albopictus and Ae. polynesiensis and related species. In all of these species, DENV may be transmitted vertically from infected female to her offspring; however, most mosquitoes become infected when they ingest viremic blood from a person experiencing an acute DENV infection. After an extrinsic incubation period of 10-14 days, the female mosquito can transmit the virus to another human when it takes a blood meal ${ }^{17,128}$.

Pathogenesis. Infection with DENV causes a spectrum of illness ranging from subclinical infection, to mild febrile illness, to classical dengue fever, to severe and sometimes fatal hemorrhagic disease ${ }^{130}$. Classical dengue fever is an acute febrile illness that most commonly occurs in older children and adults, characterized by fever, frontal headache, myalgias and frequently arthralgias, nausea, vomiting and rash. Dengue fever may have a convalescence of several weeks. The severe form of DENV infection-DHF/dengue shock syndrome (DSS)—is a vascular leak syndrome that is thought to be precipitated by an immunological cascade beginning with infection of cells of the monocytic lineage, which produce cytokines and other chemical mediators, ultimately leading to increased vascular permeability, leakage, hypovolemia, shock and death if not corrected ${ }^{130,131}$. Less commonly, DENV infection can cause other severe disease manifestations such as massive hemorrhage, organ failure and neurological disease that mimics viral encephalitis ${ }^{128}$.

There is no chemotherapy for DENV infection. Treatment of dengue fever is symptomatic, whereas DHF/DSS requires fluid-replacement therapy. Patients can be monitored with simple clinical laboratory tests such as hematocrit to guide and maintain fluid volume. Properly managed, DHF/DSS case fatality rates can be less than $1 \%{ }^{130}$. The other severe disease manifestations are more difficult to manage and generally have a higher case-fatality rate.

The pathogenesis of DENV infection is complicated and not well understood. Data suggest that viral, imunopathogenic and other host factors have a role in disease severity ${ }^{128,130,131}$. The main risk factors for severe disease include the strain of virus, previous infection with a heterotypic DENV, age and genetic background of the person. The vascular leak syndrome (DHF/DSS), severe hemorrhagic disease and encephalopathy/encephalitis most likely have different pathogenetic mechanisms ${ }^{128}$.

Infection with one of the four DENV serotypes provides lifelong immunity to that serotype, but not to the others. A person living in an endemic area, therefore, can have four dengue infections during their lifetime, one with each serotype. The primary (first) dengue infection produces monotypic antibody to the infecting virus serotype. Subsequent infection with a heterotypic serotype, however, produces a massive anamnestic antibody response, with very high antibody titers that crossreact with all four virus serotypes, as well as with other flaviviruses ${ }^{132,133}$. This secondary-type antibody response cannot be reliably used to identify the infecting virus serotype because it is not uncommon for the antibody titer to the primary virus infection to be higher than that of the current infecting virus (original antigenic $\sin )^{134}$. Identification of the infecting virus serotype in secondary infections must therefore rely on virus isolation or on the use of nucleic acid amplification tests such as reverse transcription polymerase chain reaction ${ }^{135}$.

Changing epidemiology. Dengue fever is an old disease, but in the past 25 years there has been a marked global emergence and re-emergence of epidemic dengue, with more frequent and larger epidemics associated with more severe disease ${ }^{128,129,136,137}$ (Figs. 4 and 5). The reasons for this global pandemic are not fully understood, but are thought to result from major demographic and societal changes that have occurred since World War II ${ }^{128}$. During the war, both the viruses and the principal urban mosquito vector became widely distributed in the urban centers of southeast Asia. The economic development and massive unplanned urbanization that followed the conflict, combined with lack of mosquito control, resulted in increased epidemic activity and the emergence of DHF in that region in the 1950s and 1960s. A similar pattern of unplanned urbanization and lack of mosquito control occurred in the Pacific and the American tropics in the 1970s and 1980s. With the advent of modern airplane travel and the increased movement of people, many of them infected and incubating DENV, there has been a profound global geographic expansion of DENV and their mosquito vectors (Fig. 6). In summary, unprecedented population growth (primarily in urban centers of tropical countries), the increased movement of viruses in infected humans through modern transportation and the lack of effective mosquito 
a Dengue/dengue hemorrhagic fever, average annual number of cases reported to WHO, 1955-2001

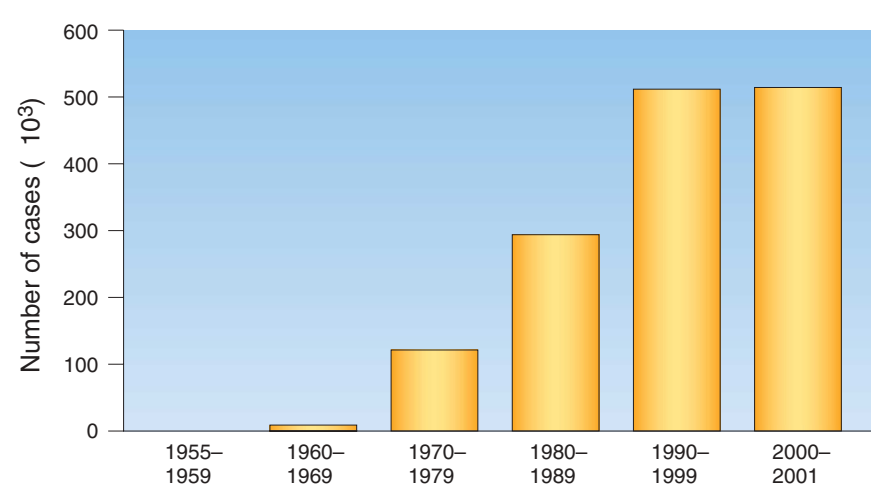

b Countries in the world reporting DHF cases, 1950-2000 (cumulative)*

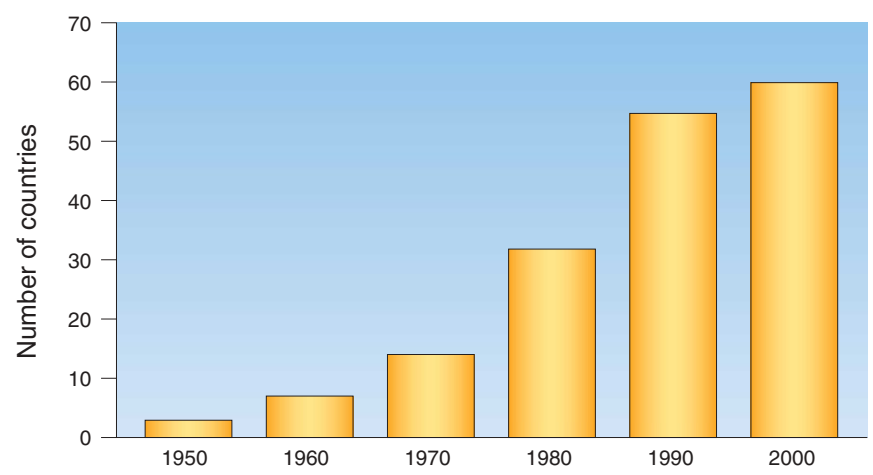

Figure 4 The global resurgence of dengue and dengue hemorrhagic fever over the past half century, by incidence (a) and by country (b).

control have all contributed to the marked increase in epidemic activity. In 2004, over 2.5 billion people lived in risk areas for dengue infection (Fig. 6); it is estimated that between 50-100 million cases of dengue fever, 500,000 cases of DHF/DSS and more than 20,000 deaths occur each year ${ }^{129,138}$. Dengue is therefore the most important arboviral disease of humans.

Prevention and control. Currently, the only way to prevent or control dengue transmission is to control the principal vector mosquito, Ae. aegypti ${ }^{138}$. Although successful control programs were implemented in the American region in the 1950s and 1960s, the programs were disbanded after epidemic activity ceased. In the 1970s and 1980s, Ae. aegypti reinfested most of the countries where it had been eliminated ${ }^{139}$. These programs have never been successfully reimplemented.

At present, there is no vaccine for dengue viruses, although several candidates are at various stages of development ${ }^{64,140,141}$. To be effective, a dengue vaccine must protect against all four virus serotypes. For use in countries where dengue is endemic, a vaccine must be safe for use in children 9-12 months of age, must be economical and should provide long-lasting protective immunity (ideally $>10$ years).

Several approaches are being used to develop dengue vaccines. A live, attenuated vaccine is thought to provide the most complete and lasting immunity. At present, there are three such vaccine candidates under development by Mahidol University-Aventis-Pasteur, by the US Army-GlaxoSmithKline and by the National Institutes of Health $(\mathrm{NIH})^{64,140,141}$. Attenuation of the Mahidol and US Army candidates was achieved by passage in primary dog kidney cells; the latter candidate had a final passage in fetal rhesus lung cells ${ }^{142,143}$. The NIH has attenuated its candidate vaccines by introducing a 30-nucleotide, nonlethal mutation in the $3^{\prime}$ untranslated region ${ }^{144}$.

Several groups have also constructed chimeric viruses using various infectious clones as backbones. A group at Acambis has inserted the prM and $\mathrm{E}$ genes of the four DENV serotypes into the 17D yellow fever backbone $^{145}$. A group at the Center for Disease Control has constructed chimeras of DEN-1, DEN-3 and DEN-4 by inserting the prM and $\mathrm{E}$ genes of these serotypes into an infectious clone of the Mahidol PDK-53 DEN-2 LAV ${ }^{146}$. A NIH group has used an infectious clone of their LAV DEN-4 candidate for the same purpose ${ }^{147}$. All of these chimeric candidate vaccines seem promising in primate studies. The 17-D YFV chimeras have recently undergone a phase 1 trial in humans, but results are not yet available.

The US Navy has developed a DEN-1 DNA candidate vaccine that has shown promise in primate studies ${ }^{148}$, but the antibody levels and persistence of antibody are of concern. Finally, Hawaii Biotech, Inc., developed a recombinant, subunit, tetravalent vaccine by inserting subunit proteins representing the amino-terminal $80 \%$ of the E protein for each serotype plus the entire NS1 protein of DEN-2 into modified vaccinia Ankara recombinants grown in Drosophila melanogaster cells ${ }^{149}$. Studies in primates have shown a robust neutralizing antibody response.

In summary, there are at least six tetravalent candidate dengue vaccines that are in or near clinical trial in humans. The Pediatric Dengue Vaccine Initiative funded by the Bill and Melinda Gates Foundation was founded to facilitate bringing one or more of these promising candidate vaccines to fruition ${ }^{150}$.
Global distribution of dengue virus serotypes, 1970

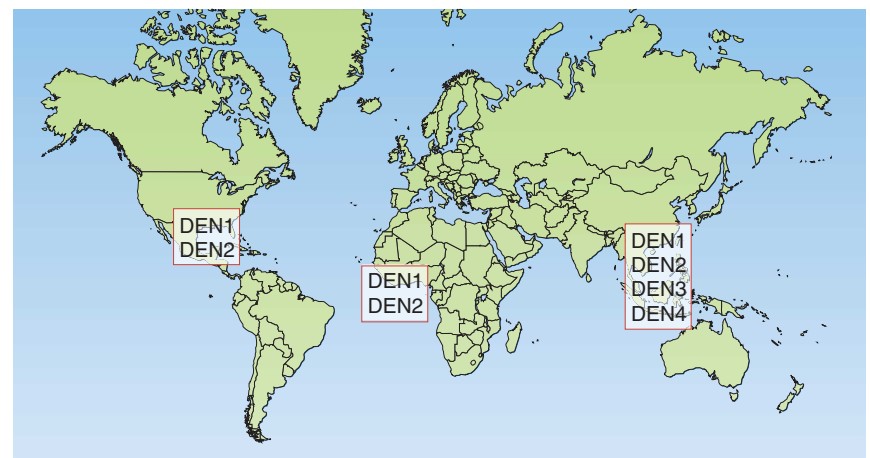

Global distribution of dengue virus serotypes, 2004

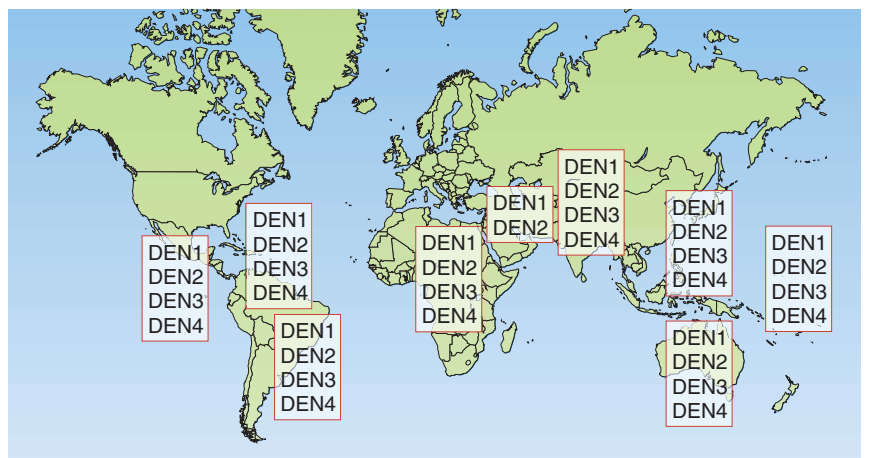

Figure 5 The change in distribution of dengue serotypes over the past 30 years. 


\section{REVIEW}

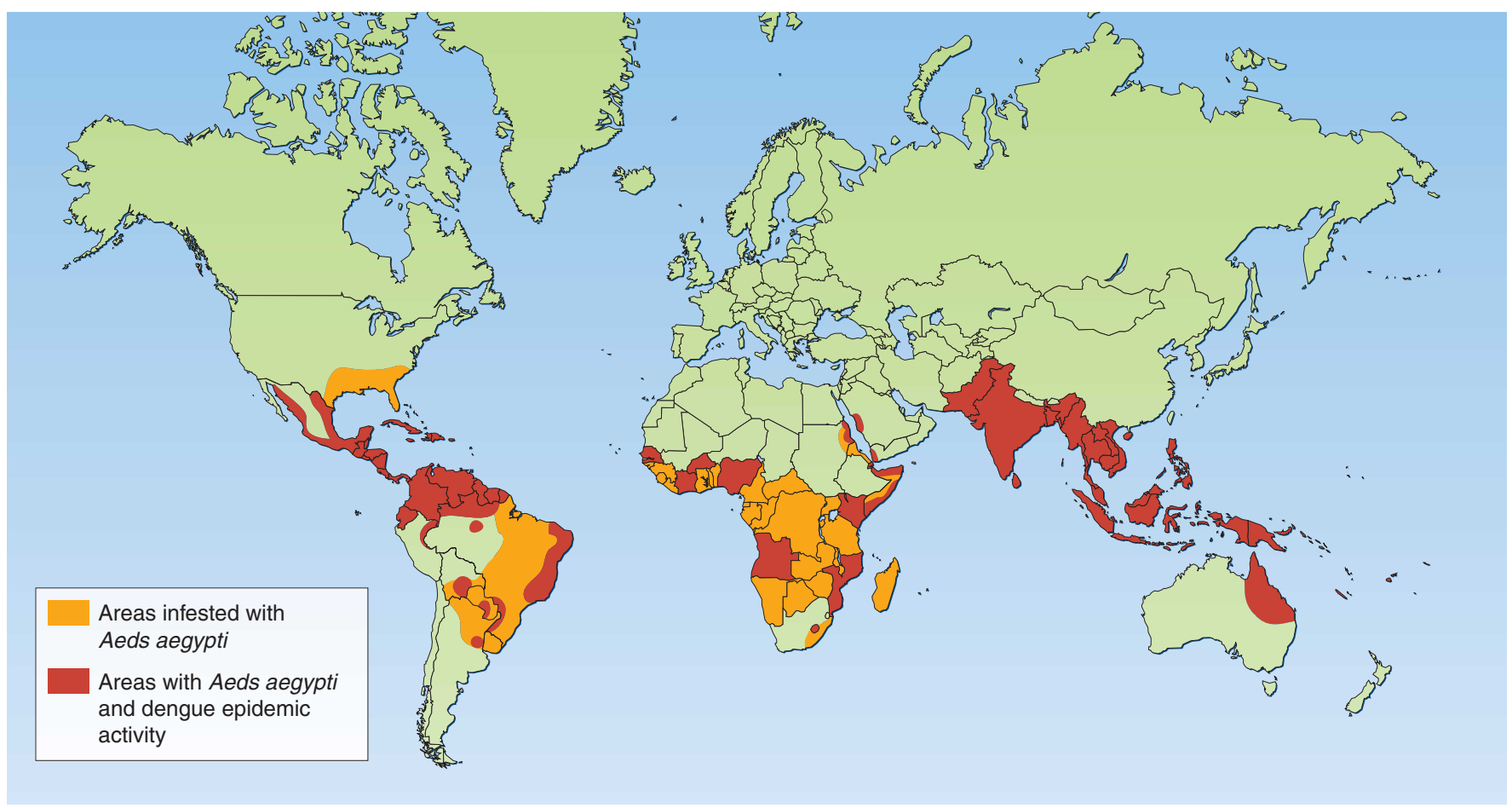

Figure 6 Dengue: its current distribution, and countries with Ae. aegypti and at risk of introduction.

\section{Comments and conclusions}

The above discussion has clearly shown that the resurgence and spread of three of the most important mosquito-borne flaviviruses are complex and result from a different combination of factors for each virus. So, for JEV, the two major factors seem to be virus spread through infected migratory and vagrant birds and the development of new rice paddies, leading to increased vector breeding conditions and an attraction to various water birds, which together provide ideal conditions for virus establishment. Initial transmission cycles between birds and paddy field-breeding mosquitoes are followed by further amplified transmission with village pigs as the vertebrate hosts. Contributory factors may also include changed land usage, deforestation, water impoundments for irrigation and favorable climatic conditions.

For WNV, spread also depends on migratory and vagrant avian species, but WNV seems to use a broader avian host range. The mechanism by which the virus spread into North America is not known, although various suggestions have been put forward, including the importation of an infected mosquito in an aircraft, the arrival of an infected traveler with a high viremia, the illegal importation of an infected bird, or through a viremic migratory bird blown into North America by a storm. Notably, Japanese encephalitis serological group viruses seem able to establish and/or coexist with each other, despite their close antigenic relationships. So, WNV coexists with JEV in India and with MVEV in Australasia, and is now establishing in the SLEVenzootic area of North America. Similarly, JEV has established in the MVEV-endemic areas of northern Australasia. In the Torres Strait and Papua New Guinea, three viruses-MVEV, JEV and WNV (Kunjin strain)—coexist. In addition, MVEV and WNV have coexisted for many years in Australia.

The factors involved in the resurgence of dengue fever/DHF are very different. The resurgence over the past 50 years has been strongly linked to urbanization and the concurrent establishment of peri-urban shantytowns with their lack of reliable water and sewage systems, and to the enormous increase in the international transport of people and commodities ${ }^{18}$. The lack of reliable water systems necessitates the collection and storage of water, which consequently increases the potential for Ae. aegypti breeding. These factors result in increased urban transmission cycles and allow the geographic spread of the virus through the movement of viremic travelers.

In addition to the movement of viremic travelers, the increased movement and establishment of vector mosquito species are also relevant. Mosquitoes can be readily transported by ship in deck cargo such as car tires and heavy machinery, setting up breeding cycles in small pools of trapped rain water, or by air as stowaways in an aircraft. Indeed there are many examples of the spread and establishment of Ae. aegypti and Ae. albopictus by these routes ${ }^{151}$. The control of Ae. aegypti continues to be a major global public health problem, but as a result of a combination of complacency, lack of research into new and environmentally safe insecticides, and unfunded mosquito control programs, most countries have had ineffectual mosquito control programs for many years ${ }^{18}$. There have also been examples of the spread and establishment of other major vector species, such as the incursion of $C x$. gelidus, a major Asian vector of JEV, into northern Australia, and the species from which the initial isolate of genotype $1 \mathrm{JEV}$ was made in 2000 (ref. 152).

There are various additional examples of flavivirus movement and establishment in which these and other factors have been implicated. These include the effect of water impoundment and irrigated agriculture in an arid area of northwest Australia on the increased incidence of $\mathrm{MVEV}^{153}$, and the probable role of bird migration in the movement of the African flavivirus, USUV, the closest flavivirus to JEV, into central Europe ${ }^{154}$. USUV appeared for the first time in 2001 as the cause of avian mortality in Austria; large numbers of birds, particularly Eurasian blackbirds (Turdus merula), died in Vienna and the surrounding areas ${ }^{154}$. The virus seems now to have become established in the area 
and now threatens to spread elsewhere in various European wild bird species $^{155}$. Serological evidence suggesting the presence of USUV in wild birds, as well as that of WNV, has recently been reported in the United Kingdom ${ }^{156}$.

There has also been a resurgence of the other major mosquito-borne flavivirus, YFV, in Africa over the past two decades ${ }^{18,157}$, and epizootic yellow fever occurred in Kenya for the first time in the early $1990 \mathrm{~s}^{158}$. This has led to concerns that, with the increased density and distribution of Ae. aegypti mosquitoes and the rise in air travel, there is an increased risk of introduction and spread of yellow fever to North and Central America, the Caribbean and Asia ${ }^{159}$. Interestingly, YFV has never been reported in Asia although it has almost certainly been imported. Various suggestions have been put forward to account for this, such as possible crossprotection or competition from other flaviviruses such as DENV and JEV, the low probability of a rare viremic traveler being bitten by an Ae. aegypti mosquito in an area with sufficient mosquitoes to maintain transmission, and the possibility that Asian strains of Ae. aegypti mosquitoes are less able to transmit YFV $^{12,18,160}$

The examples of the emerging flaviviruses described here show the ease and propensity with which these viruses can spread to emerge and establish in new geographic areas, and the importance of human activities in providing many of the conditions conducive to both movement and establishment. It is clear that these and other viruses with similar etiologies have the capacity to continue spreading and there will doubtless be many other examples of emergent arboviruses in the future. Indeed, the establishment of many exotic mosquito vectors in different areas of the world can only assist in this future emergence. No temperate, subtropical or tropical area of the world should be complacent about the possibility of new epidemic flavivirus activity; it is clear that the world of modern transportation will ensure all areas are at risk, and it is also clear that the public health infrastructure in most countries is inadequate to deal with such activity. The importance of international collaboration in improving surveillance, prevention and control programs for arboviral and other zoonotic diseases cannot be overemphasized.

\section{COMPETING INTERESTS STATEMENT}

The authors declare competing financial interests; see the Nature Medicine website for details.

Published online at http://www.nature.com/naturemedicine/

1. Morse, S.S. Factors in the emergence of infectious diseases. Emerg. Infect. Dis. 1, 7-15 (1995).

2. Heinz, F.X. et al. Family Flaviviridae, in Virus Taxonomy. 7th Report of the International Committee on Taxonomy of Viruses (eds. van Regenmortel, M.H. et al.) 859-878 (Academic, San Diego, 2000).

3. Lindenbach, B.D. \& Rice, C.M. Flaviviridae: The viruses and their replication, in Fields Virology $4^{\text {th }}$ edn (eds. Knipe, D.M. \& Howley, P.M.) 991-1042 (Lippincott Williams \& Wilkins, Philadelphia, 2001).

4. Westaway, E.G. \& Blok, J. Taxonomy and evolutionary relationships of flaviviruses, in Dengue and Dengue Hemorrhagic Fever (eds. Gubler, D.J. \& Kuno, G.) 147-173 (CAB International, London, 1997).

5. Marin, M.S., Zanotto, P.M., Gritsun, T.S. \& Gould, E.A. Phylogeny of TYU, SRE, and CFA virus: different evolutionary rates in the genus Flavivirus. Virology 206, 1133-1139 (1995).

6. Zanotto, P.M., Gould, E.A., Gao, G.F., Harvey, P.H. \& Holmes, E.C. Population dynamics of flaviviruses revealed by molecular phylogenetics. Proc. Natl. Acad. Sci. USA 93, 548-553 (1996).

7. Kuno, G., Chang, G.J., Tsuchiya, K.R., Karabatsos, N. \& Cropp, C.B. Phylogeny of the genus Flavivirus. J. Virol. 72, 73-83 (1998).

8. Billoir, F. et al. Phylogeny of the genus Flavivirus using complete coding sequences of arthropod-borne viruses and viruses with no known vector. J. Gen. Virol. 81 781-790 (2000).

9. Gaunt, M.W. et al. Phylogenetic relationships of flaviviruses correlate with their epidemiology, disease association and biogeography. J. Gen. Virol. 82, 1867-1876 (2001).

10. Gould, E.A., de Lamballerie, X., Zanotto, P.M.A. \& Holmes, E.C. Evolution, epidemiology, and dispersal of flaviviruses revealed by molecular phylogenies. Adv. Virus Res. 57, 71-103 (2001).

11. Gould, E.A., de Lamballerie, X., Zanotto, P.M.A \& Holmes, E.C. Origins, evolution, and vector/host coadaptations within the genus Flavivirus. Adv. Virus Res. 59, 277-314 (2003).

12. Gould, E.A., Moss, S.R. \& Turner, S.L. Evolution and dispersal of encephalitic flavivruses. Arch. Virol. Suppl. 18, 65-84 (2004).

13. Gould, E.A. Evolution of Japanese encephalitis serocomplex viruses. Curr. Top. Microbiol. Immunol. 267, 391-404 (2002).

14. Gritsun, T.S., Lashkevich, V.A. \& Gould, E.A. Tick-borne encephalitis. Antiviral Res. 57, 129-146 (2003).

15. Porterfield, J.S. The basis of arbovirus classification. Med. Biol. 53, 400-405 (1975).

16. Calisher, C.A. et al. Antigenic relationships between flaviviruses as determined by cross-neutralization tests with polyclonal antisera. J. Gen. Virol. 70, 37-43 (1989).

17. Gubler, D.J. Dengue and dengue haemorrhagic fever: its history and resurgence as a global public health problem, in Dengue and Dengue Hemorrhagic Fever (eds. Gubler, D.J. \& Kuno, G.) 1-22 (CAB International, London, 1997).

18. Gubler, D.J. The global emergence/resurgence of arboviral diseases as public health problems. Arch. Med. Res. 33, 330-342 (2002).

19. Institute of Medicine. Emerging Infections: Microbial Threats to Health in the United States (eds. Lederberg, J., Shope, R.E. \& Oaks, S.C.) (National Academy Press, Washington DC, 1992).

20. Institute of Medicine. Microbial Threats to Health in the United States: Emergence, Detection and Response (eds. Smolinski, M.S., Hamburg, M.S. \& Lederberg, J.) (National Academy Press, Washington DC, 2003).

21. Mackenzie, J.S., Barrett, A.D.T. \& Deubel, V. The Japanese encephalitis serological group of Flaviviruses: a brief introduction to the group. Curr. Top. Microbio. Immunol. 267, 1-10 (2002).

22. Solomon, T. \& Vaughn, D.W. Pathogenesis and clinical features of Japanese encephalitis and West Nile virus infections. Curr. Top. Microbiol. Immunol. 267, 171-194 (2002).

23. Burke, D.S. \& Leake, C.J. Japanese encephalitis, in The Arboviruses: Epidemiology and Ecology Vol. 3 (ed. Monath, T.P.) 63-92 (CRC, Boca Raton, Florida, 1988).

24. Solomon, T. \& Winter, P.M. Neurovirulence and host factors in flavivirus encephalitis-evidence from clinical epidemiology. Arch. Virol. Suppl. 18, 161-170 (2004).

25. Solomon, T. et al. Poliomyelitis-like illness due to Japanese encephalitis virus. Lancet 351, 1094-1097 (1998).

26. Scherer, W.F. Ecological studies of Japanese encephalitis in Japan. Parts I-IX. Am. J. Trop. Med. Hyg. 8, 644-722 (1959).

27. Buescher, E.L. \& Scherer, W.F. Ecological studies of Japanese encephalitis virus in Japan. IX. Epidemiologic correlations and conclusions. Am. J. Trop. Med. Hyg. 8, 719-722 (1959).

28. Innis, B.L. Japanese encephalitis, in Exotic Viral Infections (ed. Porterfield, J. S.) 147-173 (Chapman \& Hall, London, 1995).

29. Endy, T.P. \& Nislak, A. Japanese encephalitis virus: ecology and epidemiology. Curr. Top. Microbiol. Immunol. 267, 11-48 (2002).

30. Vaughn, D.W. \& Hoke, C.H. The epidemiology of Japanese encephalitis: prospects for prevention. Epidemiol. Rev. 14, 197-221 (1992).

31. Umenai, T., Krzysko, R., Bektimerov, T.A. \& Assaad, F.A. Japanese encephalitis current worldwide status. Bull. WHO 63, 625-631 (1985).

32. Igarashi, A. et al. Detection of West Nile and Japanese encephalitis viral genome sequences in cerebrospinal fluid from acute encephalitis cases in Karachi, Pakistan. Microbiol. Immunol. 38, 827-830 (1994).

33. Prasad, S.R. et al. An epidemic of encephalitis in Haryana: serologic evidence of Japanese encephalitis in a few patients. Indian J. Pediatr. 30, 905-910 (1993).

34. Dhanda, V. et al. Virus isolation from wild-caught mosquitoes during an encephalitis outbreak in Kerala in 1996. Indian J. Med. Res. 106, 4-6 (1997).

35. Hanna, J.N. et al. An outbreak of Japanese encephalitis in the Torres Strait, Australia, 1995. Med. J. Aust. 165, 256-260 (1996).

36. Ritchie, S.A. et al. Isolation of Japanese encephalitis from Culex annulirostris in Australia. Am. J. Trop. Med. Hyg. 56, 80-84 (1997).

37. Mackenzie, J.S. et al. Emergence of Japanese encephalitis virus in the Australasian region, in Factors in the Emergence of Arbovirus Diseases (eds. Saluzzo, J.F. \& Dodet, B.) 191-201 (Elsevier, Paris, 1997).

38. Hanna, J.N. et al. Japanese encephalitis in north Queensland, 1998. Med. J. Aust. 170, 533-536 (1999).

39. Kanamitsu, M. et al. Geographic distribution of arbovirus antibodies in indigenous human populations of the Indo-Australian archipelago. Am. J. Trop. Med. Hyg. 28, 351-363 (1979).

40. Marshall, I.D. Murray Valley and Kunjin encephalitis, in The Arboviruses: Epidemiology and Ecology Vol. 3 (ed. Monath, T.P.) 151-189 (CRC, Boca Raton, Florida, 1988).

41. Chen, W.R., Tesh, R.B. \& Rico-Hesse, R. Genetic variation of Japanese encephalitis virus in nature. J. Gen. Virol. 71, 2915-2922 (1990).

42. Chen, W.R., Rico-Hesse, R. \& Tesh, R.B. A new genotype of Japanese encephalitis virus from Indonesia. Am. J. Trop. Med. Hyg. 47, 61-69 (1992).

43. Ni, H. \& Barrett, A.D.T. Nucleotide and deduced amino acid sequence of the structural protein genes of Japanese encephalitis viruses from different geographic locations. J. Gen. Virol. 76, 401-407 (1995).

44. Paranjpe, S. \& Banerjee, K. Phylogenetic analysis of the envelope gene of Japanese encephalitis virus. Virus Res. 42, 107-117 (1996).

45. Williams, D.T., Wang, L.-F., Daniels, P.W. \& Mackenzie, J.S. Molecular characterization of the first Australian isolate of Japanese encephalitis virus, the FU strain. 
J. Gen. Virol. 81, 2471-2480 (2000)

46. Uchil, P.D. \& Satchidanandam, V. Phylogenetic analysis of Japanese encephalitis virus: envelope gene based analysis reveals a fifth genotype, geographic clustering, and multiple introductions of the virus into the Indian subcontinent. Am. J. Trop. Med. Hyg. 65, 242-251 (2001).

47. Tsuchie, H. et al. Genotypes of Japanese encephalitis virus isolated in three states in Malaysia. Am. J. Trop. Med. Hyg. 56, 153-158 (1997)

48. Pyke, A.T. et al. The appearance of a second genotype of Japanese encephalitis virus isolated in the Australasian region. Am. J. Trop. Med. Hyg. 65, 747-753 (2001).

49. Ma, S.-P. et al. Short report: a major genotype of Japanese encephalitis virus currently circulating in Japan. Am. J. Trop. Med. Hyg. 69, 151-154 (2003).

50. Nga, P.T. et al. Shift in Japanese encephalitis virus (JEV) genotype circulating in northern Vietnam: implications for frequent introductions of JEV from Southeast Asia to East Asia. J. Gen. Virol. 85, 1625-1631 (2004).

51. Yang, D.K. et al. Molecular characterisation of full-length genome of Japanese encephalitis virus (KV1899) isolated from pigs in Korea. J. Vet. Sci. 5, 197-205 (2004).

52. Twiddy, S.S. \& Holmes, E.C. The extent of homologous recombination in members of the genus Flavivirus. J. Gen. Virol. 84, 429-440 (2003).

53. Yun, S.-I. et al. Molecular characterization of the full-length genome of the Japanese encephalitis virus strain K87P39. Virus Res. 96, 129-140 (2003).

54. Tsai, T.F. Factors in the changing epidemiology of Japanese encephalitis and West Nile fever. in Factors in the Emergence of Arbovirus Diseases (eds. Saluzzo, J.F. \& Dodet, B.) 179-189 (Elsevier, Paris, 1997).

55. Mackenzie, J.S. et al. Japanese encephalitis as an emerging virus: the emergence and spread of Japanese encephalitis virus in Australasia. Curr. Top. Microbiol. Immunol. 267, 49-73 (2002).

56. Ritchie, S.A. \& Rochester, W. Wind-blown mosquitoes and introduction of Japanese encephalitis into Australia. Emerg. Infect. Dis. 7, 900-903 (2001).

57. Mackenzie, J.S., Lindsay, M.D. \& Daniels, P.W. The effect of climate on the incidence of vector-borne viral diseases: the potential value of seasonal forecasting, in Applications of Seasonal Climate Forecasting in Agriculture and Natural Ecosystems-The Australian Experience (eds. Hammer, G., Nicholls, N. \& Mitchell, C.) 429-452 (Kluwer Academic Publishers, The Netherlands, 2000).

58. Min, J.-G. \& Mei, X. Progress in studies on the overwintering of the mosquito Culex tritaeniorhynchus. Southeast Asian J. Trop. Med. Publ. HIth. 27, 810-817 (1996).

59. Ming, J.-G. et al. Autumn southward 'return' migration of the mosquito Culex tritaeniorhynchus in China. Med. Vet. Entomol. 7, 323-327 (1993).

60. Asahina, S. \& Noguchi, K. Long distance flight of Culex tritaeniorynchus. Jpn. J. Sanit. Zool. 19, 110-112 (1968).

61. Innis, B.L. Japanese encephalitis, in Exotic Viral Infections (ed. Porterfield, J.S.) 147-174 (Chapman \& Hall, London, 1995).

62. Solomon, T. et al. Origin and evolution of Japanese encephalitis virus in Southeast Asia. J. Virol. 77, 3091-3098 (2003).

63. Monath, T.P. Japanese encephalitis vaccines: current vaccines and future prospects. Curr. Top. Microbiol. Immunol. 267, 105-138 (2002).

64. Chang, G.J., Kuno, G., Purdy, D.E. \& Davis, B.S. Recent advancement in flavivirus vaccine development. Expert Rev. Vaccines 3, 199-220 (2004).

65. Bistra, M.B. et al. Efficacy of a single-dose SA14-14-2 vaccine against Japanese encephalitis: a case control study. Lancet 358, 791-795 (2001).

66. Monath, T.P. et al. Clinical proof of principle for ChimeriVax: recombinant live, attenuated vaccines against flavivirus infections. Vaccine 20, 1004-1018 (2002).

67. Beasley, D.W.C. et al. Protection against Japanese encephalitis virus strains representing four genotypes by passive transfer of sera raised against ChimeriVax-JE experimental vaccine. Vaccine 22, 3722-3726 (2004).

68. Smithburn, K.C., Hughes, T.P., Burke, A.W. \& Paul, J.H. A neurotropic virus isolated from the blood of a native of Uganda. Am. J. Trop. Med. 20, 471-492 (1940).

69. Petersen, L.R. \& Roehrig, J.T. West Nile virus: a reemerging global pathogen. Emerg. Infect. Dis. 7, 611-614 (2001).

70. Murgue, B., Zeller, H. \& Deubel, V. The ecology and epidemiology of West Nile virus in Africa, Europe and Asia. Curr. Top. Microbiol. Immunol. 267, 196-221 (2002).

71. Hall, R.A., Broom, A.K., Smith, D.W. \& Mackenzie, J.S. The ecology and epidemiology of Kunjin virus. Curr. Top. Microbiol. Immunol. 267, 253-269 (2002).

72. Jia, X.Y. et al. Genetic analysis of the West Nile New York 1999 encephalitis virus. Lancet 354, 1971-1972 (1999).

73. Lanciotti, R.S. et al. Origin of the West Nile virus responsible for an outbreak of encephalitis in the northeastern US. Science 286, 2333-2337 (1999).

74. Lanciotti, R.S. et al. Complete genome sequences and phylogenetic analysis of West Nile virus strains isolated from the United States, Europe, and the Middle East. Virology 298, 96-105 (2002).

75. Berthet, F.X. et al. Extensive nucleotide changes and deletions within the envelope glycoprotein gene of Euro-African West Nile viruses. J. Gen. Virol. 78, 2293-2297 (1997).

76. Scherret, J.H., Mackenzie, J.S., Hall, R.A., Deubel, V. \& Gould, E.A. Phylogeny and molecular epidemiology of West Nile and Kunjin viruses. Curr. Top. Microbiol. Immunol. 267, 373-390 (2002)

77. Burt, F.J. et al. Phylogenetic relationships of southern African West Nile virus isolates. Emerg. Infect. Dis. 8, 820-826 (2002).

78. Lvov, D.K. et al. West Nile virus and other zoonotic viruses in Russia: examples of emerging and reemerging situations. Arch. Virol. Suppl. 18, 85-96 (2004).

79. Charrel, R.N. et al. Evolutionary relationship between Old World West Nile virus strains. Evidence for viral gene flow between Africa, the Middle East, and Europe.
Virology 315, 381-388 (2003).

80. Beasley, D.W. et al. Mouse neuroinvasive phenotype of West Nile virus strains varies depending upon virus genotype. Virology 296, 17-23 (2002).

81. Komar, N. et al. Experimental infection of North American birds with the New York 1999 strain of West Nile virus. Emerg. Infect. Dis. 9, 311-322 (2003).

82. Malkinson, M. \& Banet, C. The role of birds in the ecology of West Nile virus in Europe and Africa. Curr. Top. Microbiol. Immunol. 267, 309-322 (2002).

83. McLean, R.G., Ubico, S.R., Bourne, D. \& Komar, N. West Nile virus in livestock and wildlife. Curr. Top. Microbiol. Immunol. 267, 272-308 (2002).

84. Rappole, J.H. et al. Migratory birds and West Nile virus. J. Appl. Microbiol. 94, 47S-58S (2003).

85. Solomon, T. Flavivirus encephalitis. N. Engl. J. Med. 351, 370-378 (2004).

86. Hubalek, Z. \& Halouzka, J. West Nile fever-a reemerging mosquito-borne viral disease in Europe. Emerg. Infect. Dis. 5, 643-650 (1999).

87. Lillibridge, K.M. et al. The 2002 introduction of West Nile virus into Harris County, Texas, an area historically endemic for St. Louis encephalitis. Am. J. Trop. Med. Hyg. 70, 676-681 (2004).

88. Iwamoto, $\mathrm{M}$ et al. Transmission of West Nile virus from an organ donor to four transplant recipients. N. Engl. J. Med. 348, 2196-2203 (2003).

89. Pealer, L.N. et al. Transmission of West Nile virus through blood transfusion in the United States in 2002. N. Engl. J. Med. 349, 1236-1245 (2003).

90. Intrauterine West Nile virus infection-New York, 2002. MMWR Morb. Mortal. Wkly. Rep. 51, 1135-1136 (2002).

91. Possible West Nile virus transmission to an infant through breast-feedingMichigan, 2002. MMWR Morb. Mortal. Wkly. Rep. 51, 877-878 (2002).

92. West Nile virus infection among turkey breeder farm workers-Wisconsin, 2002. MMWR Morb. Mortal. Wkly. Rep. 52, 1017-1019 (2003).

93. Possible dialysis-related West Nile virus transmission-Georgia, 2003. MMWR Morb. Mortal. Wkly. Rep, 53, 738-739 (2004).

94. Petersen, L.R. \& Marfin, A.A. West Nile virus: a primer for the clinician. Ann. Intern. Med. 137, 173-179 (2002).

95. Watson, J.T. et al. Clinical characteristics and functional outcomes of West Nile fever. Ann. Intern. Med. 141, 360-365 (2004).

96. Sejvar, J.J. et al. Neurologic manifestations and outcome of West Nile virus infection. J. Am. Med. Assoc. 290, 511-515 (2003).

97. O'Leary, D.R. et al. The epidemic of West Nile virus in the United States, 2002. Vector Borne Zoonotic Dis. 4, 61-70 (2004).

98. Sejvar, J.J. et al. Acute flaccid paralysis and West Nile virus infection. Emerg. Infect. Dis. 9, 788-793 (2003).

99. Guarner, J. et al. Clinicopathologic study and laboratory diagnosis of 23 cases with West Nile virus encephalomyelitis. Hum. Pathol. 35, 983-990 (2004).

100. Southam, C.M. \& Moore, A.E. Induced virus infections in man by the Egypt isolates of West Nile virus. Am. J. Trop. Med. Hyg. 3, 19-50 (1954).

101. Kleinschmidt-DeMasters, B.K. et al. Naturally acquired West Nile virus encephalomyelitis in transplant recipients: clinical, laboratory, diagnostic, and neuropathological features. Arch. Neurol. 61, 1210-1220 (2004).

102. Perelygin, A.A. et al. Positional cloning of the murine flavivirus resistance gene. Proc. Natl. Acad. Sci. USA 99, 9322-9327 (2002).

103. Diamond, M.S. et al. B cells and antibody play critical roles in the immediate defense of disseminated infection by West Nile encephalitis virus. J. Virol. 77, 2578-2586 (2003).

104. Wang, T. et al. IFN- $\gamma$-producing $\gamma \delta$ T cells help control murine West Nile virus infection. J. Immunol. 171, 2524-2531 (2003).

105. Shrestha, B. \& Diamond, M.S. Role of $\mathrm{CD}^{+} \mathrm{T}$ cells in control of West Nile virus infection. J. Virol. 78, 8312-8321 (2004).

106. Gea-Banacloche, J. et al. West Nile virus: pathogenesis and therapeutic options. Ann. Intern. Med. 140, 545-553 (2004).

107. Solomon, T. et al. Interferon $\alpha-2 a$ in Japanese encephalitis: a randomised doubleblind placebo-controlled trial. Lancet 361, 821-826 (2003).

108. Granwehr, B.P. et al. West Nile virus: where are we now? Lancet Infect. Dis. 4, 547-556 (2004).

109. Kimura, R. \& Hotta, S. On the inoculation of dengue virus into mice. (In Japanese). Nippon Igaku 3379, 629-633 (1944)

110. Sabin, A.B. Research on dengue during World War II. Am. J. Trop. Med. Hyg. 1, 30-50 (1952).

111. Hammon, W.M. et al. New hemorrhagic fevers of children in the Philippines and Thailand. Trans. Assoc. Am. Physicians 73, 140-155 (1960).

112. Twiddy, S.S., Holmes, E.C. \& Rambaut, A. Inferring the rate and time-scale of dengue virus evolution. Mol. Biol. Evol. 20, 122-129 (2003).

113. Holmes, E.C. \& Twiddy, S.S. The origin, emergence and evolutionary genetics of dengue virus. Inf. Genetics Evol. 3, 19-28 (2003).

114. Rico-Hesse, R. Molecular evolution and distribution of dengue viruses type 1 and 2 in nature. Virology 174, 479-493 (1990).

115. Lewis, J.A. et al. Phylogenetic relationships of dengue-2 viruses. Virology 197, 216-224 (1993).

116. Rosen, L. The emperor's new clothes revisited, a reflection on the pathogenesis of dengue hemorrhagic fever. Am. J. Trop. Med. Hyg. 26, 337-343 (1997).

117. Gubler, D.J., Reed, D., Rosen, L. \& Hitchcock, J.D., Jr. Epidemiologic, clinical, and virologic observations on dengue in the Kingdom of Tonga. Am. J. Trop. Med. Hyg. 27, 581-589 (1978).

118. Lanciotti, R.S., Lewis, J.G., Gubler, D.J. \& Trent, D.W. Molecular evolution and epidemiology of dengue-3 viruses. J. Gen. Virol. 75, 65-75 (1994).

119. Rico-Hesse, R. et al. Origins of dengue type 2 viruses associated with increased pathogenicity in the Americas. Virology 230, 244-251 (1997). 
120. Leitmeyer, K.C. et al. Dengue virus structural differences that correlate with pathogenesis. J. Virol. 73, 4738-4747 (1999).

121. Messer, W.B. et al. Emergence and global spread of a dengue serotype 3, subtype III virus. Emerg. Infect. Dis. 9, 800-809 (2003).

122. Gubler, D.J. et al. Virological surveillance for dengue haemorrhagic fever in Indonesia using the mosquito inoculation technique. Bull. WHO 57, 931-936 (1979).

123. Bennett, S.N. et al. Selection-driven evolution of emergent dengue virus. Mol. Biol. Evol. 10, 1650-1658 (2003).

124. Holmes, E.C., Worobey, M. \& Rambaut, A. Phylogenetic evidence for recombination in dengue virus. Mol. Biol. Evol. 16, 405-409 (1999).

125. Tolou, $\mathrm{H}$. et al. Evidence for recombination in natural populations of dengue virus type 1 based on the analysis of complete genome sequences. J. Gen. Virol. 82 , 1283-1290 (2001).

126. Uzcategui, N.Y. et al. The molecular epidemiology of dengue type 2 virus in Venezuela: evidence for in situ virus evolution and recombination. J. Gen. Virol. 82 2945-2953 (2001).

127. Holmes, E.C. \& Burch, S.S. The causes and consequences of genetic variation in dengue virus. Trends Microbiol. 8, 74-77 (2000).

128. Gubler, D.J. Dengue and dengue hemorrhagic fever. Clin. Microbiol. Rev. 11 480-496 (1998).

129. Gubler, D.J. Epidemic dengue/dengue hemorrhagic fever as a public health, social and economic problem in the $21^{\text {st }}$ century. Trends Microbiol. 10, 100-103 (2002).

130. World Health Organization. Dengue Haemorrhagic Fever, Diagnosis, Treatment, Prevention and Control Edn. 2 (World Health Organization, Geneva, 1997).

131. Kurane, I. \& Ennis, F.A. Immunopathogenesis of dengue virus infections, in Dengue and Dengue Hemorrhagic Fever (eds. Gubler, D.J. \& Kuno, G.) 273-290 (CAB International, London, 1997)

132. Innis, B.L. Dengue and dengue hemorrhagic fever, in Exotic Viral Infections (ed. Porterfield, J.S.) 103-145 (Chapman \& Hall, London, 1995).

133. Kuno, G. Serodiagnosis of flaviviral infections and vaccinations in humans. $A d v$. Virus Res. 61, 3-65 (2004).

134. Halstead, S.B., Rojanasuphot, S. \& Sangkawibha, N. Original antigenic sin in dengue. Am. J. Trop. Med. Hyg. 32, 154-156 (1983).

135. Guzman, M.G. \& Kouri, G. Dengue diagnosis, advances and challenges. Int. J. Infect. Dis. 8, 69-80 (2004).

136. Halstead, S.B. The XXth century dengue pandemic: need for surveillance and research. Rapp. Trimest. Stat. Sanit. Mond. 45, 292-298 (1992).

137. Gubler, D.J. \& Clark, G.G. Dengue/dengue hemorrhagic fever: the emergence of a global health problem. Emerg. Infect. Dis. 1, 55-57 (1995)

138. World Health Organization. Strengthening implementation of the global strategy for dengue fever/dengue haemorrhagic fever prevention and control. Report of the Informal Consultation, 18-20 October 1999 (World Health Organization, Geneva, 2000).

139. Gubler, D.J. Aedes aegypti and Aedes aegypti-borne disease control in the 1990s: top down or bottom up. Am. J. Trop. Med. Hyg. 40, 571-578 (1989).

140. Kinney, R.M. \& Huang, C.Y.H. Development of new vaccines against dengue fever and Japanese encephalitis. Intervirology 44, 176-197 (2001).

141. Halstead, S.B. \& Deen, J. The future of dengue vaccines. Lancet 360, 1243-1245 (2002).
142. Bhamarapravati, N. \& Yoksan, S. Live attenuated tetravalent dengue vaccine. Vaccine 18 Suppl. 2, 44-47 (2000).

143. Sun, W. et al. Vaccination of human volunteers with monovalent and tetravalent live-attenuated dengue vaccine candidates. Am. J. Trop. Med. Hyg. 69 Suppl. 6, 24-31 (2003).

144. Whitehead, S.S. et al. A live attenuated dengue virus type 1 vaccine candidate with a 30-nucleotide deletion in the 3'untranslated region is highly attenuated and immunogenetic in monkeys. J. Virol. 77, 1653-1657 (2003).

145. Guirakhoo, F. et al. Construction, safety and immunogenicity in nonhuman primates of a chimeric yellow fever-dengue virus tetravalent vaccine. J. Virol. 75, 7290-7304 (2001).

146. Huang, C.Y.H. et al. Chimeric dengue type 2 (vaccine strain PDK-53)/Dengue type 1 virus as a potential candidate Dengue type 1 virus vaccine. J. Virol. 74, 3020-3028 (2000).

147. Whitehead, S.S. et al. Substitution of the structural genes of dengue virus type 4 with those of type 2 results in chimeric vaccine candidates which are attenuated for mosquitoes, mice and rhesus monkeys. Vaccine 21, 4307-4316 (2003).

148. Konishi, E., Yamaoka, M., Kurane, I. \& Mason, P.W. A DNA vaccine expressing dengue type 2 premembrane and envelope genes induces neutralizing antibody and memory $B$ cells in mice. Vaccine 18, 1133-1139 (2000).

149. Men, R et al. Immunization of rhesus monkeys with a recombinant of modified vaccine virus Ankara expressing a truncated envelope glycoprotein of dengue type 2 virus induced resistance to dengue type 2 virus challenge. Vaccine 18, 3113-3122 (2000).

150. Accelerating the Development and Introduction of a Dengue Vaccine for Poor Children. Hosted by: Children's Hospital No. 1 and Pasteur Institute of Ho Chi Minh City, December 5-8, 2001 (Ho Chi Minh City, Vietnam, 2001).

151. Lounibos, L.P. Invasions by insect vectors of human disease. Annu. Rev. Entomol. 47, 233-266 (2002).

152. van den Hurk, A.F. et al. Japanese encephalitis on Badu Island, Australia: the first isolation of Japanese encephalitis virus from Culex gelidus in the Australasian region and the role of mosquito host feeding patterns in virus transmission cycles. Trans. R. Soc. Trop. Med. Hyg. 95, 595-600 (2001).

153. Mackenzie, J.S. \& Broom, A.K. Old river irrigation area: the effect of dam construction and irrigation on the incidence of Murray Valley encephalitis virus, in Water Resources-Health, Environment and Development (ed. Kay, B.H.) 108-122 (Spon, London, 1998).

154. Weissenbock, H. et al. Emergence of Usutu virus, an African mosquito-borne flavivirus of the Japanese encephalitis virus group, central Europe. Emerg. Infect. Dis. 8, 652-656 (2002).

155. Weissenbock, H. et al. Usutu virus activity in Austria, 2001-2002. Microbes Infect. 5, 1132-1136 (2003).

156. Buckley, A. et al. Serological evidence of West Nile virus, Usutu virus and Sindbis virus infection of birds in the UK. J. Gen. Virol. 84, 2807-2817 (2003).

157. Robertson, S.E. et al. Yellow fever. A decade of reemergence. J. Am. Med. Assoc. 276, 1157-1162 (1996).

158. Sanders, E.J. et al. First recorded outbreak of yellow fever in Kenya, 1992-1993. I. Epidemiologic investigations. Am. J. Trop. Med. Hyg. 59, 644-649 (1998).

159. Monath, T.P. Yellow fever: an update. Lancet Infect. Dis. 1, 11-20 (2001).

160. Monath, T.P. Yellow fever, in The Arboviruses: Epidemiology and Ecology Vol. 5 (ed. Monath, T.P.) 139-231 (CRC Press, Boca Raton, 1989). 